\title{
META-ANALYSIS VARIASI MINAT BIDANG PENELITIAN PADA MAHASISWA D3 MANAJEMEN INFORMATIKA JURUSAN TEKNOLOGI INFORMASI DI POLITEKNIK NEGERI MALANG
}

\author{
Odhitya Desta Triswidrananta ${ }^{1)}$, Imam Fahrur Rozi ${ }^{2)}$, Atiqah Nurul Asri ${ }^{3)}$, Rudy Ariyanto ${ }^{4)}$ \\ Jurusan Teknologi Informasi \\ Politeknik Negeri Malang \\ ${ }^{1)}$ odhitya.desta@gmail.com
}

(Artikel diterima: Oktober 2019, direvisi: September 2019, diterima untuk terbit: Januari 2020)

\begin{abstract}
Abstrak - Berdasarkan pengalaman yang ada, kebaruan topik Laporan Akhir (LA) yang diangkat oleh para mahasiswa masih sangat rendah, bahkan ada beberapa topik yang sama namun tempat yang berbeda. Padahal prodi D3 Manajemen Informatika (MI) memiliki keunggulan dalam hal keterbaruan teknologi dimana saat ini bidang teknologi informasi sangat berkembang pesat. Permasalahan lain yang muncul kaitan dengan Laporan Akhir (LA) mahasiswa yaitu adanya permasalahan yang diangkat hampir sama. Tentunya hal ini sangat ironis dengan keunggulan prodi D3 MI itu sendiri. Oleh karena itu, perlu adanya pemetakan topik penelitian laporan akhir mahasiswa tersebut melalui meta analisis. Karya / laporan akhir yang dibuat oleh mahasiswa D3 MI adalah Laporan Akhir (LA). Hasil karya / laporan akhir mahasiswa berupa perancangan dan pembuatan perangkat lunak yang bersifat aplikatif dan laporannya. Hasil Laporan Akhir tersebut harus berorientasi pada penyelesaian suatu permasalahan yang ada di industri atau masyarakat pada saat ini serta dapat diterapkan dan dikembangkan untuk beberapa tahun kedepan. Adapun topik dari laporan akhir yang dibuat oleh mahasiswa dalam bentuk Laporan Akhir yang dihasilkan meliputi bidang kajian antara lain: 1) Sistem Informasi; 2) Jaringan Komputer; 3) Multimedia dan Game..
\end{abstract}

Kata kunci: D3 manajemen informatika; laporan Akhir; meta analisis.

\section{Pendahuluan}

Perkembangan animo masyarakat untuk kuliah pada Program Sudi (Prodi) D3 Manajemen Informatika (MI) Politeknik Negeri Malang (Polinema) dari tahun ke tahun sampai saat ini sangat tinggi dengan ditandai mahasiswa baru tiap tahunnya mencapai lebih dari 150 mahasiswa dan juga disebabkan oleh beberapa faktor. Salah satunya adalah kebutuhan di dunia kerja akan lulusan di bidang informatika yang siap kerja. Hal tersebut berdampak pada jenjang pendidikan tinggi, dimana jumlah peminatnya belakangan ini dirasakan terus meningkat karena lebih cenderung mendahulukan pendidikan baru bekerja [6].

Berdasarkan pengalaman yang ada, kebaruan topik Laporan Akhir (LA) yang diangkat oleh para mahasiswa masih sangat rendah, bahkan ada beberapa topik yang sama namun tempat yang berbeda. Padahal prodi D3 Manajemen Informatika (MI) memiliki keunggulan dalam hal keterbaruan teknologi dimana saat ini bidang teknologi informasi sangat berkembang pesat. Tentunya hal ini sangat ironis dengan keunggulan prodi D3 MI itu sendiri. Oleh karena itu, peneliti tertarik untuk memetakan topik penelitian laporan akhir mahasiswa tersebut melalui meta analisis.

Meta analisis adalah suatu teknik yang digunakan untuk merangkum temuan dua penelitian atau lebih dengan tujuan untuk menggabungkan, meninjau dan meringkas penelitian atau data sebelumnya. selain itu dengan menggunakan meta analisis berbagai pertanyaan dapat diselidiki berdasarkan data yang telah ditemukan [8].

Meta analisis merupakan analisis kuantitatif dan menggunakan sejumlah data yang cukup banyak serta menerapkan metode statistik dengan mempraktekkannya dalam mengorganisasikan sejumlah informasi yang berasal dari sampel besar yang fungsinya untuk melengkapi maksud- maksud lainnya untuk mengorganisasikan dan menggali informasi sebanyak mungkin dari data yang diperoleh, serta sebagai suatu teknik ditujukan untuk menganalisis kembali hasil-hasil penelitian yang diolah secara statistik berdasarkan pengumpulan data primer [2].

Beberapa kelebihan penelitian meta analisis seperti 1) Lebih sedikit subjektivitas dan judgement dibanding 3 metode lain yang telah dikenal. 2) Karena merupakan pendekatan kuantitatif, maka banyak mengambil sampel, sehingga hasil bisa lebih representatif. Hasil akhirnya dinamakan "effect size". 3) Meta-analysis memungkinkan mengkombinasikan berbagai macam hasil penelitian yang telah ada sebelumnya. 4) Metode ini fokus pada pengakumulasian impact dari hasil-hasil yang tidak signifikan sehingga bisa menghasilkan suatu hasil yang signifikan. 5) Metode ini juga dapat menjwab pertanyaan seputar kesenjangan hasil yang terjadi dari studi yang bermacam-macam. 6) Pada penelitian bidang bisnis, Meta analisis membuat organizational behaviour yang baik.

Di samping memiliki kelebihan, penelitian dengan menggunakan meta analisis juga memiliki kelemahan, seperti 1) Karena banyaknya sampel yang diambil, maka kemungkinan akan terjadi/memiliki sampel - sampel yang bias serta data-data yang tidak perlu. 2) Meta analisis seringkali membuat hasil yang dipublikasikan hanya yang signifikan saja, sedangkan yang tidak signifikan tidak dipublikasikan. 3) Metode bersifat meng-aggregat-kan serta merata-ratakan sesuatu. Jadi sesuatu yang berbeda bisa jadi dipandang sama oleh metode ini. 4) Metode ini tidak cocok diterapkan bila sampel datanya kecil. 5) Bisa saja terjadi metodological error. 6) Varians yang disebabkan oleh faktor luar. 7) Ketidaksempurnaan validitas konstruk dependen dan independen [5].

Berdasarkan latar belakang masalah yang telah 
dikemuakakan sebelumnya, maka tujuan dari penelitian ini yaitu untuk mengetahui 1) Gambaran peta penelitian laporan akhir mahasiswa program studi D3 Manajemen Informatika Polinema. 2) Penelitian laporan akhir mahasiswa memiliki relevansi dengan visi-misi program studi D3 Manajemen Informatika Polinema. Dimana diketahui bahwa karya tulis ilmiah adalah sebuah laporan yang dituangkan dan dimuat dalam bentuk media cetak maupun elektronik yang berisi sebuah paparan hasil penelitian atau kajian sebagaimana yang telah diperbuat oleh seseorang atau sebuah kelompok peneliti dengan memenuhi persyaratan dan etika ilmu pengetahuan yang telah disepakati dan ditaati bersama dan ini juga termasuk sebagai komunikasi ilmiah. Selain itu karya ilmiah juga dikatakan sebagai suatu karya yang berada dalam rumpun bidang ilmu pengetahuan (science) dan teknologi yang diperoleh sesuai dengan prosedur dan sifat keilmuannya yang didasari oleh hasil observasi objek dan hasil penelitian orang lain sebagai dasar untuk dibuktikan, namun tetap disusun menurut metode tertentu dengan sistematika penulisan yang santun serta dapat dipertanggungjawabkan kebenarannya / keilmiahannya. Sedangkan tujaun dari pembuatan karya tulis ilmiah yaitu membuktikan sejauh hipotesis, memberikan penjelasan, memberi komentar atau penilaian, memberi saran jika dibutuhkan serta menyampaikan sanggahan secara ilmiah pula jika tidak seperti dengan apa yang terjadi sebenarnya. Hal tersebut juga di ungkapkan oleh [1] bahwa artikel hasil penelitian adalah artikel ilmiah yang telah ditulis dari hasil suatu hasil kegiatan penelitian dan melewati tahapan-tahan tertentu sehingga menghasilkan sebuah tulisan yang dapat dipertanggung jawabkan.

\section{Metode}

Metode ini meliputi penerimaan hasil penemuan masing-masing kajian pada effect size (D). Untuk studi yang membandingkan kelompok eksperimental dan kelompok kontrol, effect size dihitung dengan mengurangkan rerata skor terhadap kelompok kontrol pada dependent variable dari rerata kelompok eksperimen dan dibagi dengan simpangan baku kelompok kontrol.

Rumus-rumus yang sama dikembangkan untuk mengubah kebanyakan statistik inferensial, misalnya rasio t, rasio $\mathrm{F}$ persentase, dan koefisien korelasi bagi effect size tersebut. Rerata effect size untuk seluruh kajian dilibatkan dalam research review yang kemudian dihitung untuk mengestimasi tipe-tipe efek dari fenomena di bawah kajian tersebut. Rumus-rumus yang sama dikembangkan untuk mengubah kebanyakan statistik inferensial, misalnya rasio $\mathrm{t}$, rasio $\mathrm{F}$ persentase, dan koefisien korelasi bagi effect size tersebut. Rerata effect size untuk seluruh kajian dilibatkan dalam research review yang kemudian dihitung untuk mengestimasi tipe-tipe efek dari fenomena di bawah kajian tersebut.

Data yang digunakan dalam penelitian ini adalah jumlah laporan akhir mahasiswa D3 Manajemen Informatika Polinema berdasarkan topik yang merupakan data dalam 3 tahun terakhir, yaitu 2016, 2017, dan 2018. Dalam meta analisis semua kajian dengan bukti yang tersedia dihubungkan dengan pertanyaan penyelidikan yang dilibatkan, tanpa memperhatikan kualitas. Menurut [4] mempertimbangkan pendekatan tersebut dengan menjelaskan bahwa secara metodologi, kajian tersebut seringkali melaporkan hasil-hasil yang sama untuk menemukannya di dalam kajian-kajian yang lebih tegas, dengan mengkombinasikan seluruh hasil kajian, yakni hasil yang dapat diterima dan yang lebih dapat dipercaya. Berikut adalah kerangka pemikiran dari meta analisis:

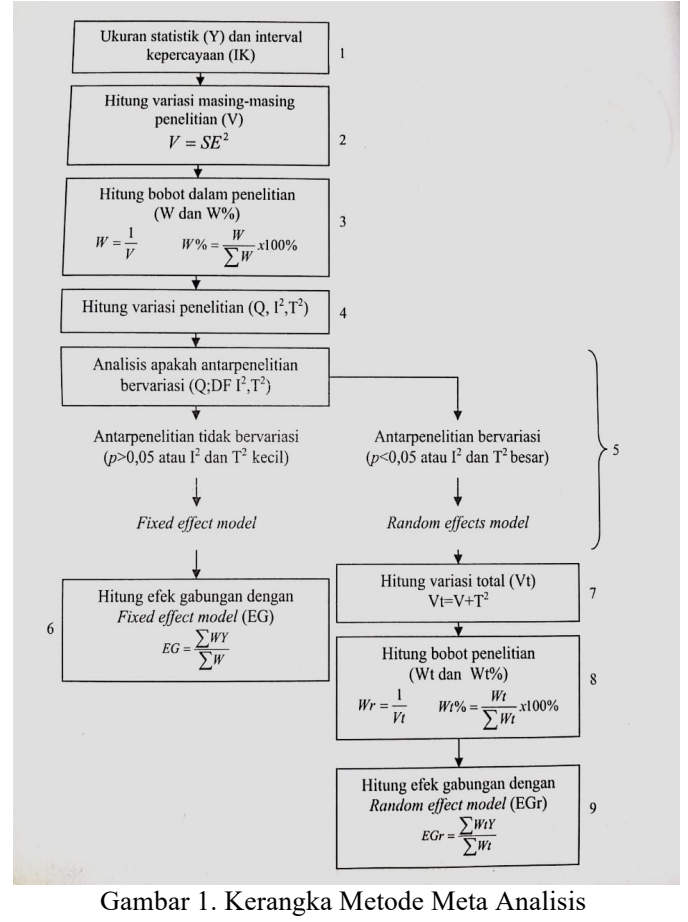

Hampir sama dengan pendapat [7] juga mengemukakan pendapat mereka mengenai tahapan-tahapan dalam melakukan penelitian meta analisis, antara lain:

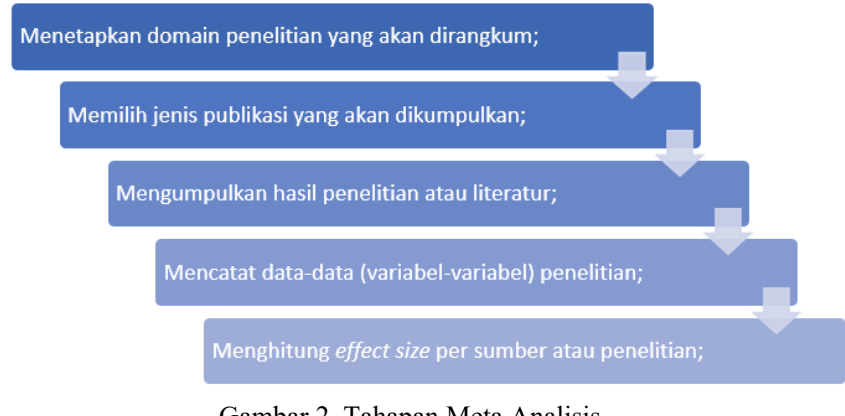

Gambar 2. Tahapan Meta Analisis

Effect size adalah indeks kuantitatif yang digunakan untuk merangkum hasil studi dalam meta-analisis. Artinya, effect size mencerminkan besarnya hubungan antar variabel dalam masing-masing studi. Pilihan indeks effect size bergantung pada jenis data yang digunakan dalam studi. Ada empat jenis data dalam penelitian, yaitu:

a. Dikotomi

Pada data yang dibangun secara dikotomi, seperti hidup/mati, sukses/gagal, ya/tidak, maka effect size yang digunakan antara lain relative risk atau risk ratio (RR), odds ratio $(\mathrm{OR})$, atau risk difference $(\mathrm{RD})$.

Misalkan sebuah meta analisis terdiri dari $\mathrm{k}$ penelitian. Penelitian tersebut mempunyai variabel hasil dikotomi atau biner. Hasil setiap penelitian dapat dipresentasikan dalam tabel kontingensi $2 \times 2$. Tabel ini memberikan informasi jumlah partisipan yang terbagi dalam dua grup, yaitu grup eksperimen dan kontrol baik yang mengalami kejadian (event) maupun tidak (no event). 
Tabel 1. Tabel kontingensi 2 x 2 untuk k penelitian

\begin{tabular}{|c|c|c|c|}
\hline Penelitian ke-1 & event & no event & Total \\
\hline Eksperimen & $a_{1}$ & $b_{1}$ & $n_{11}$ \\
\hline Kontrol & $c_{1}$ & $d_{1}$ & $n_{21}$ \\
\hline Total & $m_{11}$ & $m_{21}$ & $n_{1}$ \\
\hline Penelitian ke-2 & event & no event & Total \\
\hline Eksperimen & $a_{2}$ & $b_{2}$ & $n_{12}$ \\
\hline Kontrol & $c_{2}$ & $d_{2}$ & $n_{22}$ \\
\hline Total & $m_{12}$ & $m_{22}$ & $n_{2}$ \\
\hline$\cdot$ & $\cdot$ & $\cdot$ & $\cdot$ \\
$\cdot$ & $\cdot$ & $\cdot$ & $\cdot$ \\
$\cdot$ & $\cdot$ & $\cdot$ & $\cdot$ \\
\hline Penelitian ke-j & event & no event & Total \\
\hline Eksperimen & $a_{j}$ & $b_{j}$ & $n_{1 j}$ \\
\hline Kontrol & $c_{j}$ & $d_{j}$ & $n_{2 j}$ \\
\hline Total & $m_{1 j}$ & $m_{2 j}$ & $n_{j}$ \\
\hline
\end{tabular}

\section{Keterangan:}

$\mathrm{a}_{\mathrm{j}}$ : frekuensi event dalam grup eksperimen pada penelitian ke-j

$b_{\mathrm{j}}$ : frekuensi no event dalam grup eksperimen pada penelitian ke-j

$c_{j}$ : frekuensi event dalam grup kontrol pada penelitian ke-j $\mathrm{d}_{\mathrm{j}}$ : frekuensi no event dalam grup kontrol pada penelitian ke$\mathrm{j}$ $\mathrm{n}_{1 \mathrm{j}}$ : banyaknya partisipan pada grup eksperimen pada penelitian ke-j

$\mathrm{n}_{2 \mathrm{j}}$ : banyaknya partisipan pada grup kontrol pada penelitian ke-j

$\mathrm{m}_{1 \mathrm{j}}$ : frekuensi event pada penelitian ke-j

$\mathrm{m}_{2 \mathrm{j}}$ : frekuensi no event pada penelitian ke-j

$\mathrm{n}_{\mathrm{j}}$ : banyaknya partisipan pada penelitian $\mathrm{ke}-\mathrm{j}(\mathrm{j}=1,2, \ldots$,

$\mathrm{k})$.

b. Kontinu

Pada data yang dibangun secara kontinu, seperti kehilangan bobot, tekanan darah, maka effect size yang digunakan antara lain mean difference (MD), atau standardized mean difference (SMD).

c. Time-to-event atau survival time

Untuk data jenis ini, misalnya waktu kambuh, waktu sembuh, maka digunakan rasio hazard.

d. Ordinal

Sebuah hasil yang dikategorikan berdasarkan kategori tertentu, misal ringan/sedang/berat.

Menurut [3] Untuk menghitung effect size dengan odds ratio ada beberapa langkah. Odds ratio yang pertama adalah perbandingan odds, dimana perhitungannya dengan prosedur berikut.

$$
\mathrm{OR}=\frac{a d}{b c}
$$

Ket:

$\mathrm{OR}=$ odds ratio

$\mathrm{a}=$ jumlah yang sesuai pada kasus

$\mathrm{b}=$ jumlah yang sesuai pada kontrol

$\mathrm{c}=$ jumlah yang tidak sesuai pada kasus

$\mathrm{d}=$ jumlah yang tidak sesuai pada kontrol

Untuk perhitungan selanjutnya, OR harus ditransformasikan dengan log bilangan natural yang lebih dikenal dengan $\ln (\mathrm{OR})$. Jadi, nilai $\mathrm{Y}$ pada perhitungan ini adalah $\ln (\mathrm{OR})$. Semua perhitungan selanjutnya menggunakan $\ln (\mathrm{OR})$ atau Y. Bila kita memerlukan nilai OR, kita dapat melakukan transformasi balik dengan cara eksponensial yang lebih dikenal dengan simbol exp(Y).

Langkah selanjutnya adalah mencari standart error, dengan menggunakan persamaan dibawah ini.

$$
\mathrm{SE}=\sqrt{\frac{1}{a}}+\frac{1}{b}+\frac{1}{c}+\frac{1}{d}
$$

Ket:

$\mathrm{SE}=$ Stadart error

Setelah mendapatkan stadart error, selanjutnya kita dapat menghitung nilai interval kepercayaan min dan maks dengan persamaan dibawah ini.

$$
\mathrm{IK}=\mathrm{Y} \pm \mathrm{Z} \alpha \times \mathrm{SE}
$$

Ket:

$\mathrm{IK}=$ interval kepercayaan

$\mathrm{Z} \alpha=$ deviat baku alpha

Hasil nilai diatas nantinya masih dalam bentuk $\ln (\mathrm{OR})$. Untuk mendapatkan nilai minimal dan maksimal dalam bentuk OR, menggunakan persamaan dibawah ini.

$$
\begin{aligned}
& \text { ORmin }=\exp (Y \text { minimal }) \\
& \text { ORmaks }=\exp (Y \text { maks })
\end{aligned}
$$

Setelah menghitung standart error, selanjutnya dapat menghitung variasi yang dilanjutkan pembobotan dengan rumus dibawah ini.

$$
\begin{aligned}
& \mathrm{V}=\mathrm{SE}^{2} \\
& \mathrm{~W}=\frac{1}{V}
\end{aligned}
$$

Ket:

$\mathrm{V}=$ Variasi

$\mathrm{W}=$ Bobot

Variasi adalah kuadrat dari standart error, sedangkan bobot adalah kebalikan dari variasi. Bobot pada rumus diatas belum terstandarisasi, untuk mendapat bobot terstandarisasi harus membandingkan bobot setiap penelitian dengan bobot total dikalikan $100 \%$. Seperti rumus dibawah ini.

$$
\mathrm{W} \%=\frac{W}{\Sigma W} \times 100 \%
$$

Variasi antar data dihitung berdasarkan nilai variasi terstandarisai (Q), proporsi variasi antar data terhadap variasi total $\left(\mathrm{I}^{2}\right)$ serta varians sebenarnya $\left(\mathrm{T}^{2}\right)$. Nilai $\mathrm{Q}$ adalah variasi dalam bentuk terstandarisasi. Nilai ini digunakan untuk menghitung apakah penelitian bervariasi atau tidak secara statistik. Nilai Q akan dibandingkan dengan derajat kebebasannya untuk memperoleh nilai $p$ lebih kecil dari 0,05 yang berarti bervariasi.

Selanjutnya nilai $\mathrm{I}^{2}$ digunakan untuk menghitung proporsi variasi antar data terhadap variasi total dalam satuan $0 \%$ sampai dengan $100 \%$. Semakin besar nilainya, antar data semakin bervariasi. Sementara itu, nilai $\mathrm{T}^{2}$ digunakan untuk 
menghitung variasi antar data yang sesungguhnya dalam satuan metrik sesuai dengan ukuran statistik yang sedang diukur. Berikut rumus matematis untuk ketiga hal tersebut.

$$
\begin{aligned}
& \mathrm{Q}=\sum \mathrm{WY}^{2}-\frac{(\Sigma W Y)^{2}}{\sum W} \\
& \mathrm{I}^{2}=\frac{(Q-D F)}{Q}
\end{aligned}
$$

Ket:

$$
\begin{array}{ll}
\mathrm{Q} & =\text { Variasi terstandarisasi } \\
\mathrm{I}^{2} & =\text { Variasi total } \\
\mathrm{DF} & =\text { Degree of Freedom }
\end{array}
$$

Untuk perhitungan $T^{2}$, langkah sebelumnya harus menghitung $\mathrm{C}$ sebagai komponen subtitusi pada perhitungan $\mathrm{T}^{2}$.

$$
\begin{aligned}
& \mathrm{C}=\sum \mathrm{W}-\frac{\sum W^{2}}{\sum W} \\
& \mathrm{~T}^{2}=\frac{(Q-D F)}{C}
\end{aligned}
$$

Ket:

$$
\begin{array}{ll}
\mathrm{C} & =\text { Koefisien } \\
\mathrm{T}^{2} & =\text { Variansi sebenarnya }
\end{array}
$$

Tahap akhir dari meta analisis ini adalah perhitungan efek gabungan dimana bergantung pada pembobotan setiap penelitian. Pada fixed effect model (FEM) variasi antar kelompok dianggap tidak berperan sehingga pembobotannya hanya ditentukan oleh variasi masing-masing data. Rumus efek gabungan dan interval kepercayaannya adalah sebagai berikut.

$$
\begin{aligned}
& \mathrm{EG}=\frac{\sum W Y}{\sum W} \\
& \mathrm{SE}=\frac{1}{\sqrt{\Sigma W}} \\
& \mathrm{IK}_{\mathrm{fem}}=\mathrm{EG} \pm \mathrm{Z} \alpha * \mathrm{SE}
\end{aligned}
$$

Ket:

$\mathrm{EG}=$ Efek gabungan

$\mathrm{SE}=$ Standart error fixed effect model

$\mathrm{IK}_{\mathrm{fem}}=$ Interval kepercayaan fixed effect model

\section{HaSil dan Pembahasan}

Berdasarkan data yang diolah, meta analisis dalam penelitian ini menggunakan Odds Ratio (OR). Supaya lebih objektif, penentuan peranan variasi diuji dengan uji heterogenitas. Hipotesis nol dari uji heterogenitas adalah variasi yang tidak memberikan peranan pada variasi total. Hipotesis nol ditolak apabila nilai $p$ pada uji heterogenitas kurang dari 0,05 .

Hasil nilai OR dan interval kepercayaan dapat dilihat pada table dibawah ini.

Tabel 2. Hasil nilai or dan interval kepercayaan

\begin{tabular}{|c|c|c|}
\hline OR & Min & Maks \\
\hline 2.68 & 1.35 & 5.29 \\
\hline 1.88 & 0.99 & 3.57 \\
\hline 3.37 & 1.77 & 6.42 \\
\hline
\end{tabular}

Setelah kita melihat hasil OR dan interval kepercayaan, kita dapat melihat nilai $p$ dimana hal tersebut akan menentukan heterogenitas dari penelitian ini. Berikut adalah hasil nilai $p$.

\begin{tabular}{|c|c|c|}
\multicolumn{3}{|c}{ Tabel 3. Nilai $p$} \\
\hline $\mathrm{df}$ & $\mathrm{i} 2$ & $p$ \\
\hline 2 & 0.349 & 0.215439 \\
\hline
\end{tabular}

Dapat kita lihat bahwa nilai $p$ pada uji heterogenitas $>0,05$ maka perhitungan selanjutnya menggunakan fixed effect model, dan jika hasil nilai sebaliknya akan menggunakan random effect model. Hasil tersebut juga menentukan bahwa penelitian ini bersifat homogen atau heterogen, jika $>0,05$ maka dikatakan homogeny dan juga sebaliknya. Nilai $p$ diatas sebesar 0,215439 sehingga dapat disimpulkan bahwa penelitian ini bersifat homogen.

Nilai bobot untuk setiap masing-masing periode dapat dilihat pada table dibawah ini.

Tabel 4. Nilai bobot

\begin{tabular}{|c|c|}
\hline Tahun & Bobot $(\mathbf{\%})$ \\
\hline 2016 & 30.8 \\
\hline 2017 & 34.8 \\
\hline 2018 & 34.4 \\
\hline Total & 100 \\
\hline
\end{tabular}

Tabel diatas memperlihatkan nilai bobot untuk setiap periode, dan hasil terbesar pada tahun 2017 dengan nilai bobot $34,8 \%$. Sehingga pada periode tersebut memberikan kontribusi yang besar dalam memberikan penilaian hasil akhir dari $p$. Untuk melihat hasil dari perhitungan fixed effect model, dapat dilihat pada table dibawah ini.

Tabel 5. Hasil Fixed Effect Model

\begin{tabular}{|c|c|c|c|c|}
\hline Periode & Bobot & OR & Min & Maks \\
\hline 1 & 30.8 & 2.56 & 1.76 & 3.74 \\
\hline 2 & 34.8 & \multicolumn{3}{|l}{} \\
\cline { 1 - 2 } 3 & 34.4 & \multicolumn{3}{|l}{} \\
\hline
\end{tabular}

Hasil Odds Ratio dan interval kepercayaan efek gabungan berdasarkan fixed effect model adalah 2,56 (IK95\% 1,76 - 3,74). Secara statistik, terdapat perbedaan angka ketidaksesuaian antara topik dengan bidang keahlian dosen pembimbing. Dimana mempunyai odds ratio sebesar 1,76 sampai dengan 3,74. Secara teknis, hasil penelitian bermakna karena efek yang diperoleh $(\mathrm{OR}=2,56)$ lebih besar dibandingkan efek yang diharapkan $(\mathrm{OR}=1,5)$. Dengan demikian, hasil penelitian bermakna baik secara statistik maupun secara teknis.

Dari hasil perhitungan diatas dapat kita simpulkan bahwa antara jumlah topik laporan akhir yang diambil mahasiswa berdampak pada jumlah dosen yang sesuai dengan bidang keahliannya. Oleh karena itu dalam penentuan topik laporan mahasiswa dengan bidang keahlian para dosen harus disesuaikan jumlahnya, agar tidak terjadi atau mengurangi pembimbing laporan akhir yang tidak sesuai dengan bidang keahliannya. Dan secara statistik jika tidak agar memperhatikan effect size agar tak terlalu besar yang menandakan terdapat ketidaksesuaian yang tinggi. 


\section{KESIMPULAN DAN SARAN}

\section{A. Kesimpulan}

Berdasarkan hasil penelitian, analisis data, dan pembahasan yang telah diulas, didapatkan beberapa kesimpulan antara lain:

- Terjadi ketidaksesuaian antara topik laporan akhir dengan bidang keahlian dosen pembimbing yang dikarenakan banyaknya topik laporan akhir yang mengambil sistem informasi, sehingga banyak mahasiswa yang mendapatkan dosen pembimbing yang tidak sesuai dengan bidang keahliannya.

- Pada tahun 2017 terdapat ketidaksesuaian yang paling tinggi, dimana menyumbang $34,8 \%$ dari total data yang didapat selama 3 tahun.

- Ketidaksesuaian tersebut masih belum mencapai dua kali lipatnya karena jika melihat hasil odds ratio (OR) yaitu 2,56 dibandingkan dari hasil normal OR yaitu 1,5 .

\section{B. Saran}

Berdasarkan hasil penelitian tersebut, terdapat beberapa saran sebagai berikut:

- Bagi Jurusan Teknologi Informasi, Politeknik Negeri Malang perlu memperhatikan jumlah bidang keahlian dosen setempat, dimana disesuaikan antara jumlah ketertarikan topik yang diangkat mahasiswa pada periode selanjutnya.

- $\quad$ Bagi panitia laporan akhir, perlu membuat rasio antara jumlah dosen berdasarkan keahliannya dan topik yang diangkat para mahasiswa. Sehingga dapat mengarahkan para mahasiswa memberikan saran topik laporan akhir yang bertujuan untuk mengurangi atau menambah jika terdapat salah satu topik yang terlalu banyak diambil atau kurang diminati berdasarkan rasio dosen yang sesuai bidang keahliannya.

- Dari data yang diperoleh, terdapat kenaikan topik laporan akhir setiap tahunnya yaitu di bidang multimedia dan game. Sehingga pihak jurusan dapat mempersiapkan untuk periode selanjutnya dengan memperbanyak dosen dengan bidang keahlian tersebut. Karena pada Jurusan Teknologi Informasi adalah jurusan yang paling diminati dan perubahannya paling dinamis daripada jurusan yang lain.

- Jika diperlukan pada periode selanjutnya dapat kita hitung hasil meta analisisnya, apakah sudah ada perbaikan yang signifikan dari periode sebelumnya.

\section{DAfTAR Pustaka}

[1] Alam, Ditiro Ben, Moch.Dzulkirom AR, dan Topowijono. 2015. "Analisis Metode Springate (S-Score) sebagai Alat untuk Memprediksi Kebangkrutan Perusahaan". Jurnal Administrasi Bisnis (JAB) Vol. 21 No. 1 April 2015. Universitas Brawijaya.

[2] Bloom, J. De, Kompier, M., Geurts, S., Weerth, C. De, Taris, T., \& Sonnentag, S. 2009. "Do We Recover from Vacation? Metaanalysis of Vacation Effects on Health and Well-being". Journal of Occupational Health, 51, 13-25.

[3] Dahlan, MS. "Pengantar Meta-Analisis: Disertai Praktik dengan Excel”. Epidemiologi Indonesia, Jakarta, 2011.

[4] Glass, G.V. 1981. "Primary, Secondary, and Meta-Analysis of Research". Review of research in Education. London: Sage Publication.
[5] Hunter, J. E., Jensen, J. L., \& Rodgers, R. 2014. "The Control Group and Meta-Analysis". Journal of Methods and Measurement in the Social Science, 5(1), 3-21.

[6] Ihsan, H., \& Zaki, A. 2015. "Analisis Faktor yang Menghambat Penyelesaian Studi Mahasiswa FMIPA UNM". Jurnal SCIENTIFIC PINISI, 1(1), 25-33.

[7] Jamie DeCoster. 2004. "Meta-Analysis Notes". University of Alabama. USA.

[8] Paldam, M. 2015. "Meta-Analysis in a Nutshell : Techniques and General Findings MetaAnalysis in a Nutshell : Techniques and General Findings". Economics: The OpenAccess, OpenAssessment E-Journal, 1-14. 